\title{
Preterm labour in association with Neisseria gonorrhoeae:
}

\section{Case reports}

\author{
C J N LACEY* AND J D MILNE† \\ From the Departments of Genitourinary Medicine, *The General Infirmary, Leeds, and + Bristol Royal \\ Infirmary
}

SUMMARY We describe two cases of spontaneous rupture of the membranes, followed by premature labour at 32 and 34 weeks' gestation, in association with gonococcal infection.

\section{Introduction}

Gonococcal infections in pregnancy are thought to be uncommon in the United Kingdom, and two prospective studies reported incidences of $0 \cdot 2 \% .^{12}$ No complication of pregnancy in association with gonorrhoea has been documented. In the United States, however, studies have shown incidences ranging from $0 \cdot 5-7 \% 0^{34}$ in antenatal patients. Infections in late pregnancy have been shown to be associated with preterm rupture of the membranes, preterm labour, and clinical and histological chorioamnionitis. 567 We report two similar cases occurring in the United Kingdom.

\section{Case reports}

\section{CASE 1}

A 25 year old woman (para $2+2$ ) whose antenatal course had been uneventful, presented to the Bristol Maternity Hospital as an emergency at 32 weeks' gestation. Spontaneous rupture of the membranes had occurred 36 hours before and contractions had started 3 hours before presentation. Her temperature was $37 \cdot 8^{\circ} \mathrm{C}$. and pulse rate 120 beats/minute. On examination presentation was noted to be cephalic and the cervix was effaced; the mother was managed conservatively. Later in labour a fever of $38.0^{\circ} \mathrm{C}$ developed and a high vaginal swab was taken, but this was not received by the laboratory. A baby girl of 32 weeks' gestation was delivered whose weight was $1.54 \mathrm{~kg}$ and whose Apgar score was 6 at one minute and 9 at five minutes. Because of the

Address for reprints: Dr C J N Lacey, Department of Genitourinary Medicine, The General Infirmary at Leeds, Great George Street, Leeds LS1 3EX

Accepted for publication 17 August 1983 maternal fever in labour and prolonged rupture of the membranes, an orogastric aspirate and deep ear swab were taken from the baby. The aspirate showed 40 white cells per high power field and many Gram negative bacteria. The baby was nursed in $25 \%$ oxygen in humidified air in a headbox and given benzyl penicillin $25 \mathrm{mg}$ and gentamicin $4 \mathrm{mg}$ twice daily by intravenous injection. There was no clinical evidence of ophthalmia neonatorum. Neisseria gonorrhoeae was cultured from the orogastric aspirate and material from the deep ear swab. On the seventh postnatal day the baby was diagnosed as having necrotising enterocolitis. Metronidazole was prescribed and the baby's recovery was uneventful.

The mother developed no clinical signs of puerperal sepsis, but a full blood count at three days postpartum showed a leucocyte count of $11700 \times 10^{\circ} / 1$. She was discharged home on the sixth day, having received no antibiotic treatment. She failed to return to the postnatal clinic for further investigation. Six weeks after delivery her common law husband was shown to have asymptomatic urethral gonorrhoea but he did not name her as a sexual contact. He was treated with amoxycillin $3 \mathrm{~g}$ and probenecid $1 \mathrm{~g}$ and did not return for follow up. Ten weeks postpartum she discovered a defaulter's letter sent to him, and presented for examination. Characteristic gonococci were seen in endocervical secretions, and culture of cervical material confirmed the presence of $N$ gonorrhoeae; culture for Chlamydia trachomatis gave negative results. She was successfully treated with a single dose of amoxycillin $3 \mathrm{~g}$ given with probenecid $1 \mathrm{~g}$.

\section{CASE 2}

A 20 year old woman (para $1+0$ ) was admitted at 29 weeks' gestation with a small antepartum haemorrhage which settled with conservative treatment, 
and she was discharged home after two days. Ultrasound scanning had been performed at 14 weeks, and showed fetal maturity consistent with her dates. She was readmitted at 34 weeks' gestation 18 hours after spontaneous rupture of the membranes. She was managed conservatively, but developed a fever of $38.3^{\circ} \mathrm{C}$ in labour. Blood cultures and a high vaginal swab were taken, and she was treated with ampicillin and metronidazole given intravenously. Blood cultures were sterile but the high vaginal swab grew $N$ gonorrhoeae on New York City medium. The minimum inhibitory concentration of penicillin for this isolate was $0 \cdot 15 \mathrm{~g} / \mathrm{l}$. Two hours after antibiotic treatment was started, a boy weighing $2 \cdot 26 \mathrm{~kg}$ was delivered. Apgar scores were 5 at one minute, 5 at five minutes, and 9 at ten minutes. An orogastric aspirate and deep ear swab were taken. The aspirate showed more than 10 white cells per high power field, but both cultures were sterile. In view of the maternal fever the baby was given prophylactic antibiotics for five days. On day 8 he became unwell and was shown to have Staphylococcus albus septicaemia in association with a superficial abscess in the antecubital fossa. This was treated with intravenous cefotaxime and gentamicin, and by draining of the abscess. The baby was eventually discharged home five weeks after delivery.

The mother's fever settled the day after delivery, and postnatal recovery was uneventful. She was asked to attend the department of genitourinary medicine clinic for follow up, but would not do so.

\section{Discussion}

Both these cases presented with preterm rupture of the membranes, maternal fever in labour, positive cultures for $N$ gonorrhoeae, and fetal orogastric aspirate showing polymorphonuclear leucocytosis. Preterm rupture of the membranes is known to follow, as well as cause, infections in amniotic fluid, ${ }^{8}$ and it seems likely that the presence of the gonococcus played a part in pathogenesis in these cases.

While there have been many similar reports from the United States, there appear to be none from the United Kingdom. Gonorrhoea in pregnancy may be less common in this country, and complications therefore unusual. The established STD clinic system in the United Kingdom may also effectively remove the routine management of these conditions from the hands of the obstetrician, thus reducing awareness that they may occur. Two studies have further complicated our understanding of the effects of sexually transmitted infections in pregnancy..$^{9} 10$ Both looked at maternal infection with $C$ trachomatis, and one also studied infection with Ureaplasma urealyticum and Mycoplasma hominis. While the first showed that infection with $C$ trachomatis was significantly associated with a shorter duration of pregnancy and increased morbidity, this was not the case in the second study. Neither of them considered the role of $N$ gonorrhoeae. Preterm delivery is a major cause of perinatal mortality in this country. ${ }^{11}$ Properly designed studies to determine the role of sexually transmitted infections in this would need close co-operation between obstetricians, bacteriologists, and genitourinary physicians.

We thank Miss Gillian Turner and Dr Peter M Dunn for permission to report these cases and Dr A E Jephcott of the Public Health Laboratory, Kingsdown, Bristol for microbiological studies and helpful criticism of the manuscript.

\section{References}

1. Cassie R, Stevenson A. Screening for gonorrhoea, trichomoniasis, moniliasis and syphilis in pregnancy. Journal of Obstetrics and Gynaecology of the British Commonwealth 1973;80:48-51.

2. Sparks RA, Williams GL, Boyce JMH, Fitzgerald TC, Shelley G. Antenatal screening for candidiasis, trichomoniasis, and gonorrhoea. Brit J Vener Dis 1975;51:110-5.

3. Jones DED, Brane RG, Jones CP. Gonorrhea in obstetric patients. J Am Vener Dis Assoc 1976; 2:30-2.

4. Amstey MS, Steadman KT. Asymptomatic gonorrhea and pregnancy. J Am Vener Dis Assoc 1976;3:14-6.

5. Handsfield HH, Hodson WA, Holmes KK. Neonatal gonococcal infection. JAMA 1973;225:697-701.

6. Edwards LE, Barrada MI, Hamann AA, Hakanson EY. Gonorrhea in pregnancy. Am J Obstet Gynecol 1978; 132: 637-41.

7. Oppenheimer EH, Winn KJ. Fetal gonorrhea with deep tissue infection occurring in utero. Pediatrics 1982; 69:74-6.

8. Naeye RL, Peters EC. Causes and consequences of premature rupture of the fetal membranes. Lancet 1980; i: 192-4.

9. Martin DH, Kowsky L, Eschenbach DA, et al. Prematurity and peri-natal mortality in pregnancies complicated by maternal Chlamydia trachomatis infections. JAMA 1982; 247: 1585-8.

10. Harrison HR, Alexander ER, Weinstein L, Lewis M, Sim DA. Epidemiologic correlations of genital infections and outcomes in pregnancy. In: Mårdh PA, Holmes KK, Oriel JD, Piot P, Schacter J, eds. Chlamydial infections. Amsterdam: Elsevier Biomedical Press, 1982; 159-62.

11. Rush RW, Keirse MJNC, Howat P, Baum JD, Anderson ABM, Turnbull AC. Contribution of pre-term delivery to perinatal mortality. Br Med J 1976; ii:965-8. 